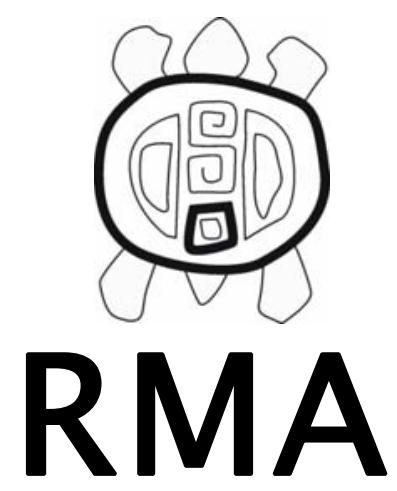

\title{
Ongamira, Intihuasi y otros recuerdos
}

Arqueología

Alberto Rex González
gonzalezrex@hotmail.com

Resumen de los Editores

La presente nota fue presentada originalmente para ser publicada en la revista Publicaciones Arqueología del CIFFyH (UNC). Debido a que dicha publicación dejó de circular hemos decidido rescatar del archivo algunas contribuciones que por motivos ajenos a los autores han quedado sin publicar. En esta primera entrega ofrecemos una mirada personal escrita por Alberto Rex González de su relación con Osvaldo Menghin mediante las vivencias ocurridas en las excavaciones de dos sitios que marcaron un hito en la Arqueología regional de Sierras Centrales y del país.

Palabras clave: Ongamira, Intihuasi, Menghin

Ongamira, Intihuasi and other memories

\begin{abstract}
from the editors
This short comunnication was presented originally to be published in the journal Publicaciones Arqueología del CIFFyH (UNC). Because this publication it is no longer available we have decided to rescue of their files some contributions that by different reasons have been without publishing. In this first delivery we offer a personal glance written by Alberto Rex González of its relation with Osvaldo Menghin during their personal experiences in the excavations of two sites that marked a landmark in the regional Archaeology of Sierras Centrales and the whole country.
\end{abstract}

Key words: Ongamira, Intihuasi, Menghin

El articulo de Philip Kohl y J. A. Pérez Gollán «Religión, Politics and Prehistory», publicado en el numero 4 del volumen 43 de Current Antropology (agosto-octubre del 2002), es muy importante debido a la objetividad científica con que los autores tratan de juzgar una personalidad que, por sus actividades y por su posición internacional, sobre todo política e ideológica, mereció juicios muy controvertidos, pero cuya gravitación en nuestras ciencias del hombre es indiscutible.

Como crecí y tuve contactos personales con Menghin durante varios años, puedo aportar algunas informaciones sobre su actuación científica local, que podría sumarse o sustraerse a tantas otras opiniones de las que sugieren las importantes actividades científicas del investigador austriaco. Más aún, porque alguna vez se intentó, interesadamente, contraponer una inexistente oposición entre sus enfoques teóricos y nuestra actividad como dos polos irreconciliables y de inevitable elección.

Por pura coincidencia, mi regreso a nuestro país, después de mi larga ausencia en los EEUU, donde había ido a estudiar antropología y arqueología, coincidió con la inserción en nuestro medio de Menghin, después de las vicisitudes que le tocó vivir como consecuencia del triunfo de los aliados y su exilio en nuestra tierra.

En realidad, el fondo de la cuestión era usar el enorme prestigio del investigador austriaco, que ya tenía entonces, tras de sí, una importante carrera personal en tres continentes, y cuyo prestigio se afianzó desde su llegada a nuestro medio por obra de José Imbelloni. Este era un investigador ítaloargentino que apoyaba ideológicamente la escuela del kultur-kreisse en nuestro medio y opositor denodado de la antropología norteamericana. 
Aunque personalmente, recién empezaba mi carrera profesional, el hecho de que tuviera formación académica en EEUU, podía oponer varios obstáculos de antecedentes al acceso a las cátedras de algunos discípulos de Imbelloni, incorporados en el Museo Etnográfico de la Universidad de Buenos Aires'.

Yo no conocía personalmente a Menghin pero sí, sabía de su prestigio internacional, de sus numerosos artículos y de la escuela del Kultur Kreisse a través de su vocero local José Imbelloni.

A muy poco de mi regreso, me había postulado y obtenido por concurso el cargo de docente (adjunto) investigador en la materia de arqueología de la carrera de antropología de la Facultad y Museo de La Plata. En los comienzos de esas tareas, recibí una Ilamada telefónica de Menghin, que se había incorporado, muy poco antes, al personal del Museo Etnográfico de Buenos Aires. Se proponía hacer unas visitas al Museo de la Plata y quería mantener una charla personal conmigo.

Teniendo en cuenta, el prestigio que rodeaba su figura, consideré importante su propuesta, que se concretó muy pocos días después y aclaró el interés que tenía de charlar conmigo, que sólo había publicado varios artículos que no atrajeron mayor interés entre los arqueólogos profesionales de la época.

Menghin fue muy concreto: había leído el trabajo en el que describíamos las excavaciones realizadas con Aníbal Montes en los abrigos de Ongamira, Córdoba (González 1990) y quería una ampliación de las circunstancias en que algunos restos humanos habían sido excavados, y sobre todo por la presencia de niveles que contenían sólo fogones y material de piedra y hueso. Remarcando el hecho de que en los espesos sedimentos de Ongamira no aparecía fragmento alguno de alfarería, no había duda que el conjunto era precerámico. Nosotros habíamos descrito este hecho sin que ningún colega le otorgara la importancia cultural que tenía. Por lo contrario, se le restaba importancia a la falta de alfarería.

Creo que la conversación con Menghin ilustra sobre cosas distintas:

1) Que el investigador europeo, pese al escaso tiempo que llevaba en el país, se había dedicado de lleno a la lectura de monografías descriptivas, aún aquellas aparecidas en publicaciones de escasa difusión, como era la nuestra de Ongamira, incluida en las Actas de un Congreso donde no faltaban algunas contribuciones ausentes de todo interés científico y además, publicaciones escasamente difundidas no fácilmente accesibles. Vale decir, que iniciada su actividad local, Menghin se dedicó de lleno a la lectura de monografías arqueológicas locales.

2) La otra conclusión es que había advertido, de inmediato, la verdadera naturaleza cultural de la estratigrafía de Ongamira.

3) Que un arqueólogo de la experiencia de Menghin, pusiera atención en la modesta excavación de un principiante de la época, no dejó de darnos bastante satisfacción, frente a la opinión profesional negativa de otros colegas locales, que restaban todo interés a la inexistencia de cerámica en el yacimiento, según fue publicado por Antonio Serrano (Serrano 1945).

Por lo tanto, cuando Menghin me propuso al final de la charla si yo estaría dispuesto a continuar las excavaciones en los yacimientos de Ongamira trabajando con é 1 , mi respuesta fue afirmativa.

Mi interés en estudiar en EEUU era aprender la técnica que en ese país se utilizaba en el terreno, y en la que la estratigrafía se aplicaba desde los comienzos del siglo. Siempre mantuve mi interés por conocer y comparar las técnicas que se utilizaban en Europa y en los EEUU. Mi principal interés era ver el trabajo y la aplicación material en el terreno de esas técnicas, de las que se carecían por completo en nuestro país, donde trabajaban los peones con pala y pico, y donde el arqueólogo tenía sólo interés en extraer piezas de valor museístico, la actitud típica vigente en toda esa época. Por lo tanto, trabajar con un arqueólogo europeo de experiencia era una oportunidad única que no se me ofrecería sino con un largo viaje y permanencia en Europa.

Antes de partir del museo, Menghin quiso conocer al director, por entonces era el doctor Emiliano McDonagh, zoólogo no demasiado interesado en arqueología, no obstante lo cual, Menghin le expresó su deseo de continuar con las excavaciones en los abrigos de Ongamira. El Dr. Mc Donagh expresó que no había un centavo (como de costumbre) para excavaciones arqueol ógicas, pero había una manera posible de contar con algunos fondos. El museo disponía de algún dinero para contrato de profesores, con lo cual Menghin podía ser contratado y llevar a cabo, con su sueldo, las excavaciones. Este asintió y estableció que ese verano nos instalábamos en Ongamira para los comienzos de nuestras tareas. Debo dar constancia, que si bien el director era muy católico y de extrema derecha, no tengo la seguridad si realmente conocía los antecedentes políticos de Menghin.

Así fue como ese verano Menghin con su mujer y yo con la mía, nos instalamos en el almacén de la familia Supaga, dueños del predio que contenía los abrigos susceptibles de ser excavados. También suministraban pensión a turistas y viajeros.

Allí pasamos muchas semanas, en las que permanecíamos todo el día, con Menghin y señora, toda la jornada realizando las excavaciones, y comentando los hallazgos. Menghin no habló de su experiencia política con el nazismo, y las pocas veces que nombró a Hitler expresó que «era un loco». Poco mencionaba a los arqueólogos internacionales, pero la sola mención de Gordon Childe le producía una alergia aguda. De su pasado reciente no hacia mención, y de sus proyectos 
futuros sólo se refería a los que serian financiados por la familia Cropp y otros capitalistas alemanes radicados en nuestro país.

De los resultados de las excavaciones de los depósitos de Ongamira, que yo no alcanzaba a comprender, fue su interpretación de la existencia de un nivel «protolítico» en la base de la estratigrafía. Personalmente, creíamos que se trataba de la periferia de fogones mezclados con desechos de talla. En nuestras excavaciones en Intihuasi, el nivel «protolítico» pareció no estar presente y por lo tanto, ser inexistente en la secuencia general para las Sierras Centrales. En cambio si era claro que los niveles de Ongamira estaban precedidos por un nivel con puntas del tipo Ayampitín.

La excavación de la Gruta de Intihuasi, se debió a un hecho fortuito, en cuya programación y ejecución Menghin no participó en lo mas mínimo, pese a lo cual en un artículo en que se historian estas excavaciones, el suscrito es mencionado como discípulo de Menghin. La realidad es que desde las excavaciones de Ongamira nuestras comunicaciones y nuestras relaciones fueron bastante fluidas. Las confirmaciones de su actividad política-universitaria durante el nazismo fueron incorporadas al conocimiento del ambiente de nuestra disciplina en forma lenta y gradual, con una buena dosis de contradicciones según las fuentes de información. A esto podemos agregar un buen ejemplo del que pude ser testigo. En 1954 se llevó a cabo en Sao Paulo (Brasil) el Congreso Internacional de Americanistas al que fui invitado por el presidente y organizador Dr. Herbert Baldus. Para mi era un hecho trascendente por varios motivos, este era el primer Congreso al que había sido invitado y segundo, sería la oportunidad de exponer frente a los colegas los resultados obtenidos en las excavaciones de la Gruta de Intihuasi, realizadas unos años antes. La exposición fue bien acogida pues no era demasiado frecuente en esa época la excavación de grutas y abrigos. La asistencia al congreso me permitió conocer muchos destacados investigadores y cambiar opiniones con figuras como Paul Rivet, Whilhem Kopper, Eric Thompson y varios otros, y volver a ver a mis compañeros de la Universidad de Columbia, como Cliff Evans y Betty Meggers. De nuestro país acudieron José Imbelloni y Marcelo Bórmida, a quien Imbelloni al presentarlo a distintos investigadores se complacía en recalcar, una y otra vez, que se trataba «del joven estudioso más capaz y preparado de los antropólogos de la nueva generación de argentinos».

Otro recuerdo que me parece interesante es el siguiente: en algún momento del receso de las sesiones del Congreso alguien se dirigió a mi y me preguntó si yo vivía en Argentina, ante mi respuesta afirmativa, preguntó si conocía a Oswald Menghin, y ante mi respuesta, nuevamente positiva, agregó: «yo he sido amigo suyo en Europa y estuve preso por los nazis, la intervención de Menghin me salvo la vida, así que llévele un gran saludo de mi parte». Me dijo que era el Conde Slavetich, al que supongo de origen croata. Otros detalles acerca de su persona los he olvidado.

Años mas tarde en el Instituto Alemán de Arqueología de Bonn, recogí de varios colegas alemanes opiniones muy distintas respecto a la actuación política de Menghin, pero en general no eran de carácter negativo.

Quiero dejar testimonio de mis relaciones con Menghin como un profesional.

De esta relación profesional he visto reproducir versiones diferentes, algunas efectivamente inexactas, como la que me adjudicaba ser uno de sus discípulos, la cual rechazo de plano, pues con relación a mi posición teórica estaba en plena identificación con la que dominaba en aquel tiempo en la Universidad de Columbia, en la que estudie. En cuanto a la práctica, la adquirí en la Universidad de Arizona en el campamento de Point of Pines. Luego me surgió una enorme apetencia por ver trabajar a algún arqueólogo europeo y la oportunidad se presentó con Menghin,

Quiero agregar para quienes continúan trabajando en la prehistoria de las Sierras Centrales, que en las primeras excavaciones de Ongamira aparecieron en niveles profundos 203 cráneos humanos fragmentados que fueron susceptibles de ser restaurados. Nosotros los llevamos a los E.E.U.U en 1946, pues pensabamos realizar su investigación completa, ya que obviamente correspondían a una etapa bastante antigua de la secuencia precerámica. Posteriormente nos inscribimos en la carrera regular de antropología de la Universidad de Columbia y el estudio no pudo realizarse.

En los abrigos de Ongamira, aun quedan espesos sedimentos, susceptibles de ser excavados; no seria difícil que en ellos aparezcan nuevos restos óseos humanos y permitan efectuar, junto con los existentes, un estudio bastante completo de la osteología de los restos correspondientes al precerámico, tema de estudio de interés para algunos jóvenes investigadores de los pueblos de las sierras centrales.

Buenos Aires, abril de 2003

\section{Bibliografía}

González, A. R. 1959. Observaciones y comentarios al trabajo de C.R. Lafon: de la cronología y origen de las culturas del Noroeste Argentino. Revista del Instituto de Antropología de la Universidad Nacional del Litoral 1 : 315-355.

González, A. R. 1985. Cincuenta años de arqueología del Noroeste Argentino (1930-1980) 
A. R. González

apuntes de casi un testigo y algo de protagonista». American Antiquity 50 (3): 505-517.

González, A. R. 1990. A cuatro décadas del comienzo de una nueva etapa. Apuntes marginales para la historia de la antropología argentina. Anuario del IEHS 5: 13-28. Instituto de Estudios Historicos y Sociales (IEHS) Universidad Nacional del Centro de la Provincia de Buenos Aires. Tandil, Argentina.

Lafón, C. R. 1958. De la cronología y origen de las culturas del Noroeste Argentino. Revista del Museo de la Plata, Nueva Serie, Sección Antropología, 5: 1-27.
Lafón, C. R. 1960. Reflexiones sobre la arqueología argentina. Anales de Arqueología y Etnología 14-15: 20-33.

Serrano, A. 1945. Los Comechingones. Serie Aborígenes Argentinos 1. Instituto de Arqueología. Lingüística y Folklore. Córdoba, Argentina.

1 El artículo de Lafón (Lafón, 1958) es más que explícito a este respecto y en la práctica lo comprueba el hecho de que todos los llamados a concurso en las cátedras de la especialidad, ealizados en la Facultad de Filosofía y Letras de la UBA, siempre ocurrieron, por «pura coincidencia», mientras yo me encontraba en el exterior. 